TITLE:

\title{
Accurate evaluation of interface state density in SiC metal-oxide- semiconductor structures using surface potential based on depletion capacitance
}

\section{AUTHOR(S):}

Yoshioka, Hironori; Nakamura, Takashi; Kimoto, Tsunenobu

\section{CITATION:}

Yoshioka, Hironori ... [et al]. Accurate evaluation of interface state density in SiC metaloxide-semiconductor structures using surface potential based on depletion capacitance. JOURNAL OF APPLIED PHYSICS 2012, 111(1): 014502.

\section{ISSUE DATE:}

2012-01-01

URL:

http://hdl.handle.net/2433/160637

\section{RIGHT:}

Copyright 2012 American Institute of Physics. This article may be downloaded for personal use only. Any other use requires prior permission of the author and the American Institute of Physics. The following article appeared in JOURNAL OF APPLIED PHYSICS 111, 014502 (2012) and may be found at http://link.aip.org/link/?jap/111/014502 


\section{AIP $\mid \begin{array}{ll}\text { Jumanal } \\ \text { Applied Physics }\end{array}$}

Accurate evaluation of interface state density in SiC metal-oxidesemiconductor structures using surface potential based on depletion capacitance

Hironori Yoshioka, Takashi Nakamura, and Tsunenobu Kimoto

Citation: J. Appl. Phys. 111, 014502 (2012); doi: 10.1063/1.3673572

View online: http://dx.doi.org/10.1063/1.3673572

View Table of Contents: http://jap.aip.org/resource/1/JAPIAU/v111/i1

Published by the American Institute of Physics.

\section{Related Articles}

Fixed charge in high-k/GaN metal-oxide-semiconductor capacitor structures

Appl. Phys. Lett. 101, 102905 (2012)

Flexible, transparent dielectric capacitors with nanostructured electrodes

Appl. Phys. Lett. 101, 103106 (2012)

Dynamic piezoresponse force microscopy: Spatially resolved probing of polarization dynamics in time and voltage domains

J. Appl. Phys. 112, 052021 (2012)

Co-sputtering yttrium into hafnium oxide thin films to produce ferroelectric properties

Appl. Phys. Lett. 101, 082905 (2012)

Safe and consistent method of spot-welding platinum thermocouple wires and foils for high temperature measurements

Rev. Sci. Instrum. 83, 084901 (2012)

\section{Additional information on J. Appl. Phys.}

Journal Homepage: http://jap.aip.org/

Journal Information: http://jap.aip.org/about/about_the_journal

Top downloads: http://jap.aip.org/features/most_downloaded

Information for Authors: http://jap.aip.org/authors

\section{ADVERTISEMENT}

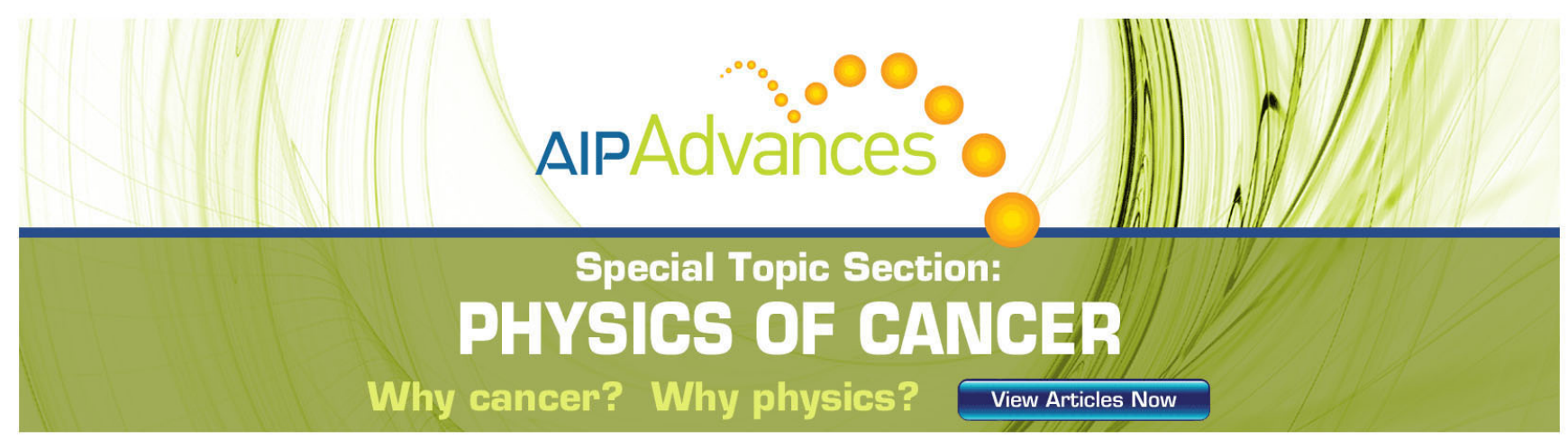




\title{
Accurate evaluation of interface state density in SiC metal-oxide-semiconductor structures using surface potential based on depletion capacitance
}

\author{
Hironori Yoshioka, ${ }^{1, a)}$ Takashi Nakamura, $^{2}$ and Tsunenobu Kimoto ${ }^{1,3}$ \\ ${ }^{1}$ Department of Electronic Science and Engineering, Kyoto University, Kyoto 615-8510, Japan \\ ${ }^{2}$ New Material Devices R\&D Center, Rohm Co. Ltd., Kyoto 615-8585, Japan \\ ${ }^{3}$ Photonics and Electronics Science and Engineering Center, Kyoto University, Kyoto 615-8510, Japan
}

(Received 5 October 2011; accepted 23 November 2011; published online 3 January 2012)

\begin{abstract}
We propose a method to accurately determine the surface potential $\left(\psi_{\mathrm{S}}\right)$ based on depletion capacitance, and the interface state density $\left(D_{\mathrm{IT}}\right)$ was evaluated based on the difference between quasi-static and theoretical capacitances in $\mathrm{SiC}$ metal-oxide-semiconductor capacitors $\left(C-\psi_{\mathrm{S}}\right.$ method). We determined that this method gives accurate values for $\psi_{\mathrm{S}}$ and $D_{\text {Iт }}$. From the frequency dependence of the capacitance measured at up to $100 \mathrm{MHz}$, a significant fast-interface-state response exists at $1 \mathrm{MHz}$, which results in the overestimation of $\psi_{\mathrm{S}}$ if it is determined based on the flatband capacitance at $1 \mathrm{MHz}$. The overestimation of $\psi_{\mathrm{S}}$ directly affects the accuracy of the energy level. $D_{\mathrm{IT}}$ at a specific energy level is underestimated by the overestimation of $\psi_{\mathrm{s}}$. Furthermore, the fast interface states that respond at $1 \mathrm{MHz}$ cannot be detected by the conventional high $(1 \mathrm{MHz})-$ low method. The $C-\psi_{\mathrm{S}}$ method can accurately determine the interface state density including the fast states without high-frequency measurements. (C) 2012 American Institute of Physics. [doi:10.1063/1.3673572]
\end{abstract}

\section{INTRODUCTION}

Silicon carbide $(\mathrm{SiC})$ has been recognized as a promising material for high-power devices because of its high breakdown electric field. $\mathrm{SiC}$ power metal-oxide-semiconductor field effect transistors (MOSFETs) are SiC devices that have been commercialized. ${ }^{1} \mathrm{SiC}$ MOSFETs still suffer from low channel mobility probably because of the high density of interface states. The interface state density is characterized by high-low or conductance methods with the maximum frequency of $0.1 \sim 1 \mathrm{MHz} .^{2-14}$ The existence of fast interface states has been suggested ${ }^{15,16}$ but the fast interface states that respond to the maximum probe frequency are undetectable by these methods. Although increasing the frequency is a method to detect fast states, very high-frequency measurements are not easily obtained because of series resistance and inductance. A method based on the difference between quasi-static (low-frequency) and theoretical capacitance is valuable for the detection of fast interface states, ${ }^{17,18}$ because measurements are not required at very high frequencies. To accurately determine the interface states by this method, a very accurate surface potential and theoretical capacitance are needed. This may be the main reason why it has not been used for $\mathrm{SiC}$ MOS structures to date. The surface potential $\left(\psi_{\mathrm{S}}\right)$ can be calculated from quasi-static and oxide capacitances $\left(C_{\mathrm{QS}}\right.$ and $\left.C_{\mathrm{OX}}\right)$ using ${ }^{17,18}$

$$
\psi_{\mathrm{S}}\left(V_{\mathrm{G}}\right)=\int\left(1-C_{\mathrm{QS}} / C_{\mathrm{OX}}\right) d V_{\mathrm{G}}+A
$$

A certain ambiguity exists in the determination of the integration constant $(A)$. For example, this constant is often

\footnotetext{
a) Author to whom correspondence should be addressed. Electronic mail: yoshioka@semicon.kuee.kyoto-u.ac.jp.
}

determined based on the flatband capacitance in highfrequency measurements, assuming that the high-frequency capacitance does not include a contribution from the interface states. If the probe frequency is not high enough, the flatband capacitance contains a component of the fast interface states leading to a large error in the surface potential.

The high-low and conductance methods also need an accurate surface potential for an evaluation of the interface state density at a specific energy level. Interface state densities in SiC MOS structures, which were evaluated by highlow $^{4-9}$ or conductance ${ }^{2,3}$ methods by different groups, are widely distributed even though MOS capacitors undergoing similar processes can be compared. The variations are likely partly due to the use of an erroneous surface potential and it is important to establish an accurate and standard method to determine the surface potential and interface state density.

In this study, we propose a method to accurately determine the integration constant of the surface potential based on the depletion capacitance and to evaluate the interface state density in SiC MOS structures from the quasi-static and theoretical capacitance. We refer to the proposed method as the " $C-\psi_{\mathrm{s}}$ method" in this paper. Moreover, we increased the maximum frequency in the high-low and conductance methods to $100 \mathrm{MHz}$ using a system suitable for high frequency measurements. The interface state densities evaluated by these methods are thus compared.

\section{SAMPLE PREPARATION AND MEASUREMENT DETAILS}

The MOS capacitor that was characterized in this work consisted of a 32-nm-thick oxide formed by dry oxidation at $1300^{\circ} \mathrm{C}$ on an n-type $4 \mathrm{H}-\mathrm{SiC}$ (0001) epilayer. The SiC epilayer was $8.4 \mu \mathrm{m}$ thick and was doped with nitrogen to $1.33 \times 10^{16} \mathrm{~cm}^{-3}$. The thickness and resistivity of the n-type 
$\mathrm{SiC}$ substrate were $335 \mu \mathrm{m}$ and $0.022 \Omega \mathrm{cm}$, respectively. A circular Ni electrode (gate) with a diameter of $604 \mu \mathrm{m}$ was used.

Measurements were carried out at room temperature $(T=304 \mathrm{~K})$ in a dark box. The impedance was measured at probe frequencies from $1 \mathrm{kHz}$ to $100 \mathrm{MHz}$ with an oscillation voltage of $25 \mathrm{mV}$ using Precision Impedance Analyzer (4294 A, Agilent Technologies), which was connected to the sample through a probe kit (42941 A, Agilent Technologies). Using the probe kit, the probe and wire impedance can be effectively eliminated, which greatly improves the accuracy of the high frequency measurements. The quasi-static capacitance was measured with a delay time of $0.1 \mathrm{~s}$ using Quasistatic CV Meter (595, Keithley). The gate voltage was swept from depletion $(-5 \mathrm{~V})$ to accumulation $(15 \mathrm{~V})$ at a rate of about $0.1 \mathrm{~V} / \mathrm{s}$ for the voltage-sweep measurements.

\section{EXPERIMENTAL RESULTS AND ANALYTICAL PROCEDURE}

\section{A. $C-V$ measurements}

Figure 1(a) shows the quasi-static capacitance $\left(C_{\mathrm{QS}}\right)$ and the parallel-mode capacitance $\left(C_{\mathrm{P}}\right)$ measured at different frequencies for the fabricated $\mathrm{SiC}$ MOS capacitor. Figure 1(b) shows the parallel-mode conductance $\left(G_{\mathrm{P}}\right)$ measured at different frequencies. The existence of interface states can be detected at about $1 \sim 2 \mathrm{~V}$ as the peak of conductance. Figure 2 shows equivalent circuits for (a) depletion to weak accumulation and (b) strong accumulation where $C_{\mathrm{OX}}, C_{\mathrm{D}}, C_{\mathrm{IT}}$, $G_{\mathrm{PIT}}$, and $Z$ are the oxide capacitance, the semiconductor capacitance, the interface-state capacitance, the interfacestate conductance, and the series parasitic impedance, respectively. For strong accumulation, $C_{\mathrm{D}}, C_{\mathrm{IT}}$, and $G_{\mathrm{PIT}}$ can be ignored because of the infinitely large $C_{\mathrm{D}}$, and the measured $C_{\mathrm{P}}$ and $G_{\mathrm{P}}$ should be independent of gate voltage. At about $15 \mathrm{~V}$, both $C_{\mathrm{P}}$ and $G_{\mathrm{P}}$ show very little change against the gate voltage indicating that the MOS capacitor is in the strong-accumulation condition. However, $C_{\mathrm{P}}$ and $G_{\mathrm{P}}$ changed significantly depending on the frequency, which is due to a change in the series parasitic impedance. Therefore, the quasi-static capacitance at $15 \mathrm{~V}$ is assumed to be $C_{\mathrm{OX}}$, and the values of $Z(\omega)$ are determined for each frequency from the impedance measured at $15 \mathrm{~V}$ and $C_{\mathrm{OX}}$, assuming strong accumulation (Fig. 2(b)).

\section{B. Determination of the surface potential by the C $-\psi_{\text {s }}$ method}

Taking into account the $C_{\mathrm{OX}}$ and $Z$ values, $C_{\mathrm{D}}+C_{\mathrm{IT}}$ at less than $15 \mathrm{~V}$ can be determined by assuming the equivalent circuit shown in Fig. 2(a). On the other hand, the surface potential $\psi_{\mathrm{S}}\left(V_{\mathrm{G}}\right)$ can be obtained using Eq. (1), except for the integration constant $A$. The integration constant $A$ can be uniquely determined, as shown in Fig. 3, where $1 /\left(C_{\mathrm{D}}+C_{\mathrm{IT}}\right)^{2}$ is plotted against $\psi_{\mathrm{S}}$. In Fig. 3 , a linear correlation is evident for the sufficiently negative $\psi_{\mathrm{S}}$ (depletion region). At a sufficiently high frequency and upon depletion, the interface states do not respond and no inversion carriers are generated at the $\mathrm{SiC}$ MOS interface. Therefore, $C_{\mathrm{D}}+C_{\mathrm{IT}}$ can be approximated as the depletion capacitance $\left(C_{\text {dep }}\right)$
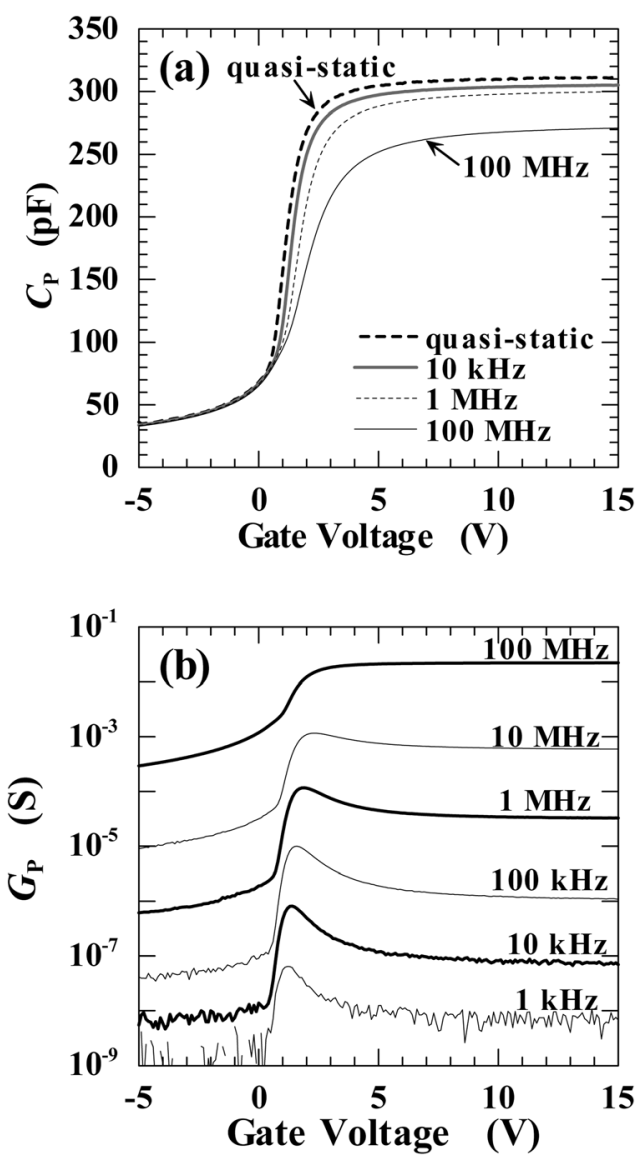

FIG. 1. (a) Capacitance-voltage and (b) conductance-voltage characteristics of a n-type $\mathrm{SiC}$ MOS capacitor measured at different frequencies (parallel mode). The quasi-static capacitance is also plotted in (a).

and a linear relationship can be established between $1 /\left(C_{\mathrm{D}}+C_{\mathrm{IT}}\right)^{2}$ and $\psi_{\mathrm{S}}{ }^{17,18}$

$$
\frac{1}{\left(C_{\mathrm{D}}+C_{\mathrm{IT}}\right)^{2}} \approx \frac{1}{C_{\mathrm{dep}}^{2}}=-\frac{2 \psi_{\mathrm{S}}}{S^{2} \varepsilon_{\mathrm{SiC}} e N_{\mathrm{D}}} \text { (depletion) }
$$

where $S\left(0.286 \mathrm{~mm}^{2}\right)$ is the area of the gate electrode, $\varepsilon_{\mathrm{SiC}}$ $\left(9.7 \varepsilon_{0}\right)$ is the dielectric constant of $\mathrm{SiC}$, and $N_{\mathrm{D}}$ is the donor concentration of the $\mathrm{SiC}$ epilayer. Based on Eq. (2), the constant $A$ was determined so that the extrapolation of the straight line should intersect the origin of the plot, as shown in Fig. 3. The donor concentration was also determined from the slope of the straight line $\left(N_{\mathrm{D}}=1.33 \times 10^{16} \mathrm{~cm}^{-3}\right)$.
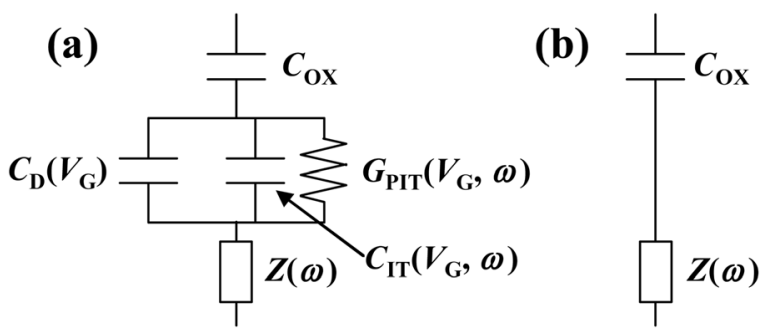

FIG. 2. Equivalent circuits for a MOS capacitor in (a) depletion to weak accumulation and (b) strong accumulation where $C_{\mathrm{OX}}, C_{\mathrm{D}}, C_{\mathrm{IT}}, G_{\mathrm{PIT}}$, and $Z$ are the oxide capacitance, the semiconductor capacitance, the interface-state capacitance, the interface-state conductance, and the series parasitic impedance, respectively. 


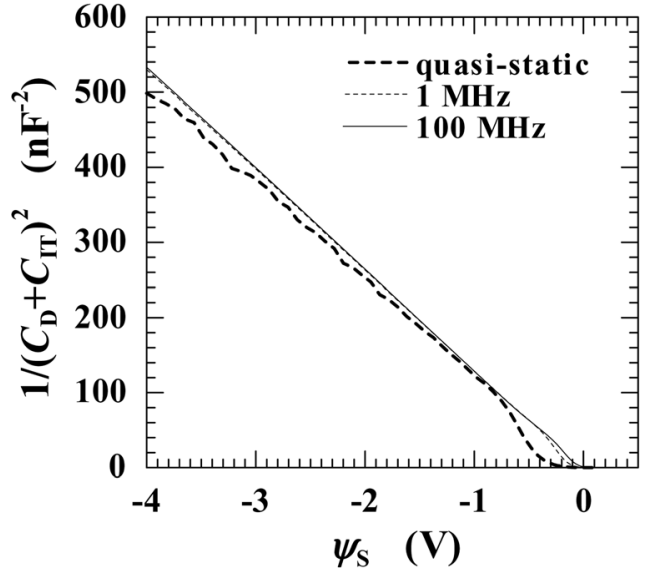

FIG. 3. $1 /\left(C_{\mathrm{D}}+C_{\mathrm{IT}}\right)^{2}$ versus surface potential $\psi_{\mathrm{S}}$ for depletion at various frequencies of a n-type $\mathrm{SiC}$ MOS capacitor, which was determined from the results given in Fig. 1 .

\section{Evaluation of interface state density in the $C-\psi_{\mathrm{s}}$ method}

Using the obtained surface potential, the theoretical semiconductor capacitance $\left(C_{\mathrm{D} \text {,theory }}\right)$ can be calculated by ${ }^{17,18}$

$$
C_{\mathrm{D}, \text { theory }}\left(\psi_{\mathrm{S}}\right)=\frac{\operatorname{SeN}\left|\exp \left(\frac{e \psi_{\mathrm{S}}}{k T}\right)-1\right|}{\sqrt{\frac{2 k T N_{\mathrm{D}}}{\varepsilon_{\mathrm{SiC}}}\left\{\exp \left(\frac{e \psi_{\mathrm{S}}}{k T}\right)-\frac{e \psi_{\mathrm{S}}}{k T}-1\right\}}}
$$

assuming that there are no holes in the n-type SiC. Figure 4 shows the $C_{\mathrm{D}}+C_{\mathrm{IT}}$ values plotted against $\psi_{\mathrm{S}}$ at different frequencies, where the $C_{\mathrm{D} \text {,theory }}$ calculated from Eq. (3) is also plotted. The measured $C_{\mathrm{D}}+C_{\mathrm{IT}}$ approached $C_{\mathrm{D} \text {,theory }}$ with an increase in the frequency because the carriers trapped at the interface states hardly respond to a sufficiently high frequency $\left(C_{\mathrm{IT}} \approx 0\right)$. A significant difference exists between $C_{\mathrm{D}}+C_{\mathrm{IT}}$ at $1 \mathrm{MHz}$ and $C_{\mathrm{D} \text {,theory }}$ indicating that a significant portion of the fast interface states respond at $1 \mathrm{MHz}$. In contrast, $100 \mathrm{MHz}$ seems to be almost sufficient for the interface carriers not to respond. The interface state density is given by ${ }^{17,18}$

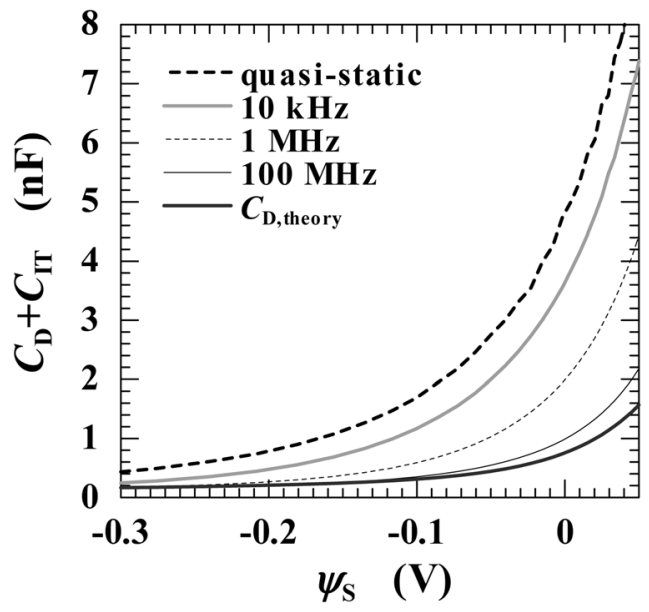

FIG. 4. $C_{\mathrm{D}}+C_{\mathrm{IT}}$ versus surface potential $\psi_{\mathrm{S}}$ at various frequencies for a ntype $\mathrm{SiC}$ MOS capacitor, which was determined from the results given in Fig. 1. The theoretical semiconductor capacitance $C_{\mathrm{D} \text {,theory }}$ is also plotted.

$$
D_{\mathrm{IT}}=\frac{\left(C_{\mathrm{D}}+C_{\mathrm{IT}}\right)_{\mathrm{QS}}-C_{\mathrm{D}, \text { theory }}}{S e^{2}},
$$

where $\left(C_{\mathrm{D}}+C_{\mathrm{IT}}\right)_{\mathrm{QS}}$ is the $C_{\mathrm{D}}+C_{\mathrm{IT}}$ measured under quasistatic conditions.

\section{Evaluation of the interface state density by the high-low method}

For the high-low method, the interface state density is given by ${ }^{17,18}$

$$
D_{\mathrm{IT}}=\frac{\left(C_{\mathrm{D}}+C_{\mathrm{IT}}\right)_{\mathrm{QS}}-\left(C_{\mathrm{D}}+C_{\mathrm{IT}}\right)_{\mathrm{HF}}}{S e^{2}}
$$

where $\left(C_{\mathrm{D}}+C_{\mathrm{IT}}\right)_{\mathrm{HF}}$ is the $C_{\mathrm{D}}+C_{\mathrm{IT}}$ measured at high frequency and is assumed to be $C_{\mathrm{D}}$. Because $C_{\mathrm{D}}+C_{\mathrm{IT}}$ approaches $C_{\mathrm{D} \text {,theory }}$ with an increase in the frequency, as shown in Fig. 4, using $\left(C_{\mathrm{D}}+C_{\mathrm{IT}}\right)_{\mathrm{HF}}$ at higher frequency gives a more accurate interface state density. Therefore, we used $\left(C_{\mathrm{D}}+C_{\mathrm{IT}}\right)_{\mathrm{HF}}$ at $100 \mathrm{MHz}$ while a $\left(C_{\mathrm{D}}+C_{\mathrm{IT}}\right)_{\mathrm{HF}}$ of $0.1 \sim 1 \mathrm{MHz}$ is usually used in the conventional high-low method.

\section{E. Evaluation of the interface state density by the conductance method}

Figure 5(a) shows the frequency dependence of $G_{\mathrm{PIT}} / \omega$ at various surface potentials. Bell-shaped peaks originate from the interface states, and the interface state density is related to $G_{\mathrm{PIT}} / \omega$ by ${ }^{10,17}$

$$
\begin{aligned}
G_{\mathrm{PIT}} / \omega= & e^{2} S D_{\mathrm{IT}} \int_{-\infty}^{+\infty} \frac{\ln \left(1+(\omega \tau \exp (\eta))^{2}\right)}{2 \omega \tau \exp (\eta)} \\
& \times \frac{1}{\sqrt{2 \pi \sigma^{2}}} \exp \left(-\frac{\eta^{2}}{2 \sigma^{2}}\right) d \eta,
\end{aligned}
$$

where the interface state density $\left(D_{\mathrm{IT}}\right)$, the time constant of the interface states $(\tau)$, and the standard deviation $(\sigma)$ are fitting parameters. The bold lines in Fig. 5(a) are $G_{\mathrm{PIT}} / \omega$ calculated from Eq. (6) to fit the experimental results. It is noted that the measurement at up to about $10 \mathrm{MHz}$ is necessary to fit correctly because the peaks exist up to about $1 \mathrm{MHz}$. The values of $\tau$ and $\sigma$ obtained by fitting are shown in Fig. 5(b) where $E_{\mathrm{C}}-E_{\mathrm{T}}$ was calculated by

$$
E_{\mathrm{C}}-E_{\mathrm{T}}=e\left(0.19 \mathrm{~V}-\psi_{\mathrm{S}}\right),
$$

taking into account the Fermi level of the $\mathrm{SiC}$ epilayer $\left(E_{\mathrm{C}}-0.19 \mathrm{eV}\right)$. The values of $\tau$ and $\sigma$ are reasonable compared to earlier reports. ${ }^{10,19,20}$

\section{DISCUSSION}

Figure 6 shows the interface state densities obtained by the $C-\psi_{\mathrm{s}}$ method $\left(C-\psi_{\mathrm{s}}\right)$, the high-low method using a high frequency of $100 \mathrm{MHz}\left(\mathrm{high}_{100 \mathrm{M}}-\mathrm{low}-\psi_{\mathrm{S}}\right)$, and the conductance method (conductance- $-\psi_{\mathrm{S}}$ ), where the $E_{\mathrm{C}}-E_{\mathrm{T}}$ of the horizontal axis was calculated from Eq. (7) using the surface potential determined by the proposed method. The use of the correct surface potential is denoted by adding the term " $-\psi_{\mathrm{s}}$." The $D_{\mathrm{IT}}$ distribution obtained by the $C-\psi_{\mathrm{s}}$ 

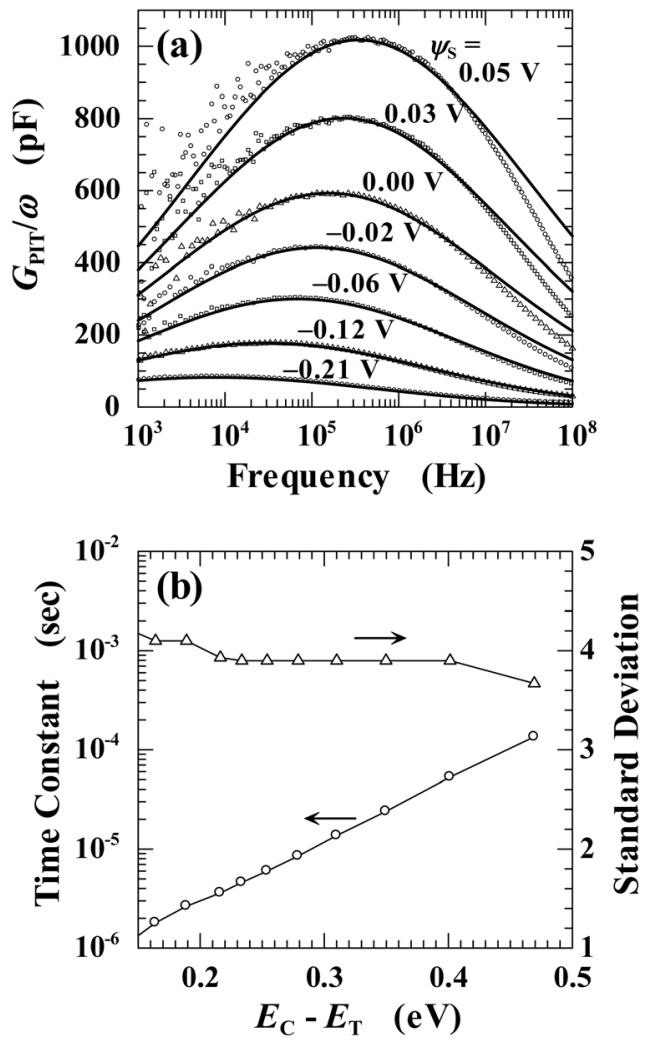

FIG. 5. (a) Interface-state conductance $G_{\mathrm{PIT}}$ normalized by angular frequency $\omega$ at various surface potentials $\psi_{\mathrm{S}}$, where the symbols are experimental results and the bold lines are theoretical results fitted to the experimental results. (b) Time constant $\tau$ and standard deviation $\sigma$ obtained by fitting $G_{\mathrm{PIT}} / \omega$.

method agrees very well with that by the conductance $-\psi_{\mathrm{S}}$ method indicating the validity of the proposed method. The surface potential and the theoretical semiconductor capacitance $\left(C_{\mathrm{D} \text {,theory }}\right)$ were correctly determined. The high $_{100 \mathrm{M}}-$ low $-\psi_{\mathrm{s}}$ method also gave an accurate interface state density because $100 \mathrm{MHz}$ was almost sufficient for the fast states not to respond.

The $D_{\text {IT }}$ distribution obtained by the conventional highlow method using a high frequency of $1 \mathrm{MHz}$, which was evaluated by the surface potential determined by a conventional method (refer to the next paragraph), is also plotted in Fig. 6 (conventional high-low). The conventional high-low

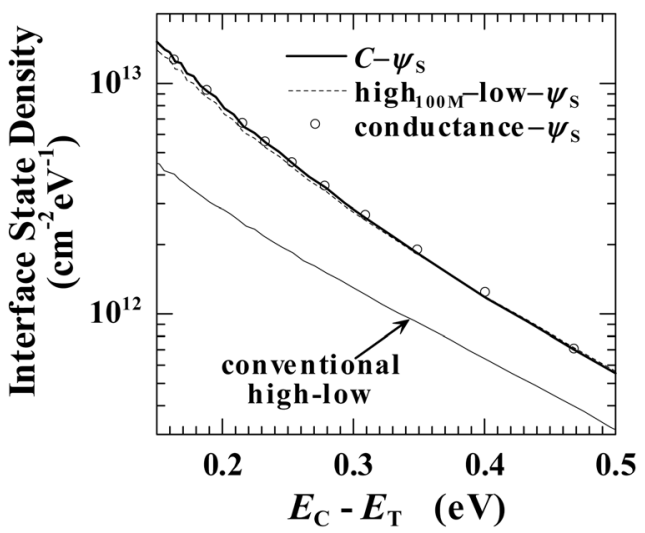

FIG. 6. Distributions of the interface state density evaluated by various methods for the same n-type SiC MOS capacitor. method underestimated the density $2 \sim 3$ times because of the following two factors. First, the fast interface states that respond to higher than $1 \mathrm{MHz}$ are not detected. Second, the surface potential error results in an error of $E_{\mathrm{C}}-E_{\mathrm{T}}$.

For the conventional high-low method, the integration constant of the surface potential was determined so that the surface potential is zero at the gate voltage at which the capacitance of $1 \mathrm{MHz}$ is equal to the theoretical flatbandcapacitance. If the conventional method is employed, the integration constant is erroneously determined because the capacitance of $1 \mathrm{MHz}$ includes $C_{\text {IT }}$. The surface potential determined by the conventional method was overestimated by $0.077 \mathrm{~V}$ for the MOS capacitor characterized in this study,

$$
\psi_{\mathrm{S}}(\text { conventional })=\psi_{\mathrm{S}}(\text { proposed })+0.077 \mathrm{~V},
$$

which results in the underestimation of $E_{\mathrm{C}}-E_{\mathrm{T}}$,

$$
E_{\mathrm{C}}-E_{\mathrm{T}}(\text { conventional })=E_{\mathrm{C}}-E_{\mathrm{T}}(\text { proposed })-0.077 \mathrm{eV} .
$$

Because the interface state density of the SiC MOS structures increases exponentially toward the conduction band edge, a small shift in $E_{\mathrm{C}}-E_{\mathrm{T}}$ results in a large change in the interface state density at specific energy levels. Therefore, the correct determination of the surface potential and $E_{\mathrm{C}}-E_{\mathrm{T}}$ is very important.

It should be emphasized that the $C-\psi_{\mathrm{S}}$ method is superior to the other methods from two points of view. First, the $C-\psi_{\mathrm{s}}$ method can detect fast interface states without frequency limits. Second, the $C-\psi_{\mathrm{s}}$ method requires simple measurements as only capacitance measurements with one voltage sweep is enough, while the conductance method needs more time-consuming $G-f$ measurements at different voltages. The $C-\psi_{\mathrm{S}}$ method can be applied to not only $\mathrm{SiC}$ MOS structures but also other metal-insulator-semiconductor structures. The requirements are that the doping concentration $\left(N_{\mathrm{D}}\right)$ is uniform near the MOS interface and no inversion (minority) carriers are collected at the interface.

\section{CONCLUSIONS}

We propose a method to accurately determine the surface potential based on depletion capacitance and evaluated the interface state density based on the difference between quasi-static and theoretical capacitances in $\mathrm{SiC}$ MOS capacitors $\left(C-\psi_{\mathrm{S}}\right.$ method). We confirmed by an agreement with the conductance methods that the proposed method gives an accurate surface potential and interface state density. Significant fast-interface-states exist that respond to $1 \mathrm{MHz}$, which results in an overestimation of the surface potential if it is determined by the flatband capacitance of $1 \mathrm{MHz}$. The overestimation of surface potential results in the interface state density at a specific energy level being underestimated by the underestimation of $E_{\mathrm{C}}-E_{\mathrm{T}}$. The high-low method using a high frequency of $1 \mathrm{MHz}$ underestimated the interface state density because the fast interface states cannot be detected. The high-low method using a high frequency of $100 \mathrm{MHz}$ gave an accurate interface state density because $100 \mathrm{MHz}$ is almost sufficient for the fast states not to respond. 
In this paper, the proposed methods were only applied for the dry-oxide MOS capacitor. We have also investigated the NO-nitride MOS capacitors with low interface state density, and we have found that the proposed methods have additionally given valuable information. By detailed investigations and analyses, we confirmed that the proposed $C-\psi_{\mathrm{S}}$ method gives accurate interface state density for the NOnitride MOS capacitors. These results will be presented in a subsequent publication.

\section{ACKNOWLEDGMENTS}

The authors appreciate the opportunity to use the impedance analyzer and technical advice from Agilent Technologies.

${ }^{1}$ Y. Nakano, T. Mukai, R. Nakamura, T. Nakamura, and A. Kamisawa, Jpn. J. Appl. Phys. 48, 04C100 (2009).

${ }^{2}$ G. Pensl, S. Beljakowa, T. Frank, K. Gao, F. Speck, T. Seyller, L. Ley, F. Ciobanu, V. Afanas'ev, A. Stesmans, T. Kimoto, and A. Schöner, Phys. Status Solidi B 245, 1378 (2008).

${ }^{3}$ M. Bassler, G. Pensl, and V. Afanas'ev, Diamond Relat. Mater. 6, 1472 (1997).

${ }^{4}$ J. Rozen, S. Dhar, M. E. Zvanut, J. R. Williams, and L. C. Feldman, J. Appl. Phys. 105, 124506 (2009).
${ }^{5}$ S. Harada, R. Kosugi, J. Senzaki, W.-J. Cho, K. Fukuda, K. Arai, and S. Suzuki, J. Appl. Phys. 91, 1568 (2002).

${ }^{6}$ P. Friedrichs, E. P. Burte, and R. Schörner, J. Appl. Phys. 79, 7814 (1996).

${ }^{7}$ S. Dhar, S.-H. Ryu, and A. K. Agarwal, IEEE Trans. Electron Devices 57, $1195(2010)$.

${ }^{8}$ M. Noborio, J. Suda, S. Beljakowa, M. Krieger, and T. Kimoto, Phys. Status Solidi A 206, 2374 (2009).

${ }^{9}$ D. Okamoto, H. Yano, K. Hirata, T. Hatayama, and T. Fuyuki, IEEE Electron Device Lett. 31, 710 (2010).

${ }^{10}$ P. Zhao, Rusli, Y. Liu, C. C. Tin, W. G. Zhu, and J. Ahn, Microelectron. Eng. 83, 61 (2006).

${ }^{11}$ J. A. Cooper, Phys. Status Solidi 162, 305 (1997).

${ }^{12}$ H. Yano, T. Kimoto, and H. Matsunami, Appl. Phys. Lett. 81, 301 (2002).

${ }^{13}$ G. Y. Chung, C. C. Tin, and J. R. Williams, Appl. Phys. Lett. 76, 1713 (2000).

${ }^{14}$ H. Li, S. Dimitrijev, H. B. Harrison, and D. Sweatman, Appl. Phys. Lett. 70, 2028 (1997).

${ }^{15}$ I. Pintilie, C. M. Teodorescu, F. Moscatelli, R. Nipoti, A. Poggi, S. Solmi, L. S. Løvlie, and B. G. Svensson, J. Appl. Phys. 108, 024503 (2010).

${ }^{16}$ V. V. Afanas'ev, A. Stesmans, F. Ciobanu, G. Pensl, K. Y. Cheong, and S. Dimitrijev, Appl. Phys. Lett. 82, 568 (2003).

${ }^{17}$ E. H. Nicollian and J. R. Brews, MOS Physics and Technology (Wiley, New York, 1982)

${ }^{18}$ D. K. Schroder, Semiconductor Material and Device Characterization, 3rd ed. (Wiley, Hoboken, N.J., 2006).

${ }^{19}$ E. Bano, T. Ouisse, L. D. Cioccio, and S. Karmann, Appl. Phys. Lett. 65, 2723 (1994).

${ }^{20}$ X. D. Chen, S. Dhar, T. Isaacs-Smith, J. R. Williams, L. C. Feldman, and P. M. Mooney, J. Appl. Phys. 103, 033701 (2008). 